\title{
The effect of hypoxia upon learned escape from carbon dioxide'
}

STEPHEN ARNOLD WEINSTEIN 2

JOHNS HOPKINS UNIVERSITY

A group of five mice was trained to press a lever to remove 4\% $\mathrm{CO}_{2}$ from its inspired air. The effect of six levels of hypoxia upon the latent period for learned escape frcm the added $\mathrm{CO}_{2}$ was determined. Mild hypoxia produced a shortened latent period, severe hypoxia a lengthened latent period. The correlation between the behavioral and ventilatory responses to $\mathrm{CO}_{2}$ and hypoxia are discussed.

We have previously reported that pigeons are capable of learning to press a switch in order to remove added $\mathrm{CO}_{2}$ from their inspired air (Weinstein, 1963, 1964). The amount of time which was taken to press the switch after the onset of the $\mathrm{CO}_{2}$ was referred to as the latent period and was shown to be inversely related to the $\mathrm{CO}_{2}$ concentration and directly related to the intertrial interval. In the present investigation we have determined the effect of graded levels of hypoxia upon the latent period for learned escape from $4 \% \mathrm{CO}_{2}$.

Von Muralt (1964) has discussed the increased sensitivity of sensory mechanisms in mild hypoxia and other investigators have described the enhancement of the ventilatory response to $\mathrm{CO}_{2}$ in hypoxic environments. Decrements in sensory and motor functions in severe hypoxia are well known and have been extensively described. Gantt (1949) has demonstrated an impairment in conditional reflex formation after exposure to severe hypoxia. On the basis of these findings in other areas, we felt that a systematic investigation to determine the effect of graded hypoxia upon a response which was determined by both stimulus strength and learned central nervous system connections (Weinstein, 1964) would be of interest.

The experimental Ss were five white mice of the BALB/C strain. Each mouse had been trained to a pre-determined level of performance in the $\mathrm{CO}_{2}$ escape conditioning situation. The criterion for the onset of experimentation was the previous performance of 100 consecutive escape responses from $4 \% \mathrm{CO}_{2}$ in air with no latency greater than $300 \mathrm{sec}$.

The apparatus was a modification of the gas mixing device which we had previously described (Weinstein, 1963).

A uniform experimental procedure was utilized for the five animals studied. At the beginning of each experimental day the mouse was placed in the chamber and allowed to rest for $15 \mathrm{~min}$. after which a programming system was turned on. This system activated relays which increased the animal's inspired $\mathrm{CO}_{2}$ to $4 \%$ with a half time for change of approximately $3 \mathrm{sec}$. (measured at the end of the chamber most distant from the source of inflow). A timing circuit was activated simultaneously with the increase in $\mathrm{CO}_{2}$ and the duration of the latent period (time until the escape response) was measured and printed out automatically. The escape response activated another timing circuit which determined the time until the next $\mathrm{CO}_{2}$ increase, in this instance $1-1 / 2 \mathrm{~min}$. Twenty-five trials were carried out in this fashion in a normoxic atmosphere. At the end of this group of trials the atmosphere was altered to one of six hypoxic levels and after a $15 \mathrm{~min}$. rest period an additional 25 trials were carried out. On each experimental day, each animal received 25 trials on air $\left(21 \% \mathrm{O}_{2}\right)$ and 25 trials at one of the six levels of $\mathrm{O}_{2}$. The order of presentation of the various low $\mathrm{O}_{2}$ mixtures was varied from animal to animal so that there would be no systematic effect of the order of exposure upon our results.

Our data indicated that mild hypoxia (above $10 \% \mathrm{O}_{2}$ ) caused a decrease in the latent period for escape from $4 \% \mathrm{CO}_{2}$ relative to performance on air. Severe hypoxia (below $7.8 \% \quad \mathrm{O}_{2}$ ) caused an increase in latent period relative to performance on air. The exact point at which the effect of hypoxia upon latent period reverses was different for each animal. It ranged from $10 \% \quad \mathrm{O}_{2}$ to $7.8 \% \quad \mathrm{O}_{2}$ in the five animals. In $5 \% \mathrm{O}_{2}$ all animals showed a marked decrement in performance. The mean data for all animals is listed in Table 1. Each latency represents the mean for five animals with the number of escape trials indicated in parentheses. The performance in $21 \% \mathrm{O}_{2}$ for the same sessions on which the indicated $\mathrm{O}_{2}$ level was used is also listed. The use of matched daily air controls in this experiment has allowed us to assess the degree of variability due to uncontrolled factors and has given a fixed criterion for the evalutation of the independent variable under investigation. The results for a single animal are illustrated in Fig. 1.

Our results indicate that the performance of a learned somatic motor response which modifies the inspired $\mathrm{CO}_{2}$

Table 1. Latency of escape from $4 \%$ carbon dioxide measured in seconds at seven levels of inspired oxygen. Number in parentheses indicate the number of escape trials.

\begin{tabular}{ll}
$21 \% \mathrm{O}_{2}$ & $15 \% \mathrm{O}_{2}$ \\
$33(75)$ & $17(75)$ \\
\hline $21 \% \mathrm{O}_{2}$ & $10 \% \mathrm{O}_{2}$ \\
$29(175)$ & $22(175)$ \\
\hline $21 \% \mathrm{O}_{2}$ & $6 \%$ \\
$27(50)$ & $61(50)$ \\
\hline
\end{tabular}

\begin{tabular}{lc}
$21 \% \mathrm{O}_{2}$ & $12 \% \mathrm{O}_{2}$ \\
$45(125)$ & $29(125)$ \\
\hline $21 \% \mathrm{O}_{2}$ & $7.8 \% \mathrm{O}_{2}$ \\
$36(125)$ & $42(125)$ \\
\hline $21 \% \mathrm{O}_{2}$ & $5 \% \mathrm{O}_{2}$ \\
$31(325)$ & $147(325)$
\end{tabular}




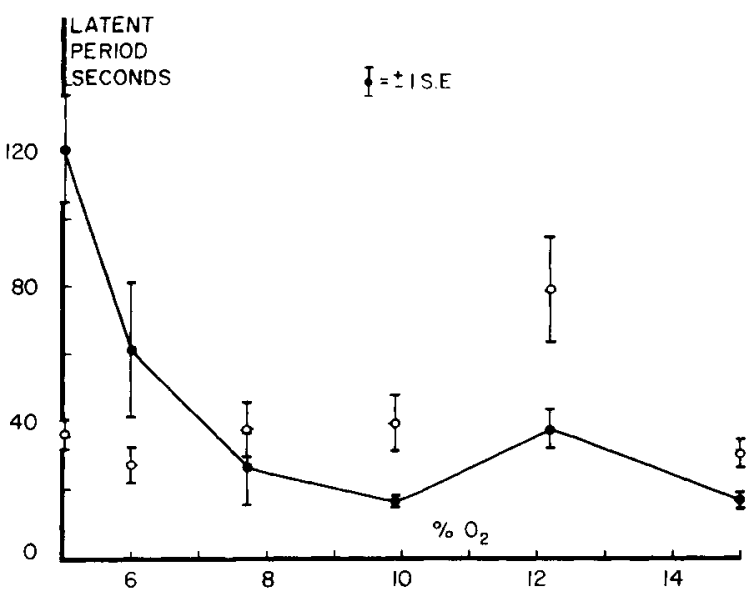

Fig. 1. The results obtained in one animal illustrating the effect of hypoxia upon latent period for learned escape from $\mathrm{CO}_{2}$. Open circles are means for escape from $\mathrm{CO}_{2}$ in $21 \% \mathrm{O}_{2}$ on the same day as the hypoxia trials indicated by the solid circle directly above or below.

concentration is a function not only of the magnitude of the $\mathrm{CO}_{2}$ stimulus, but also of the inspired $\mathrm{O}_{2}$ level. There appear to be two separate effects of hypoxia upon performance of this response, one which predominates during mild hypoxia and tends to shorten the latent period, and another which predominates in severe hypoxia and lengthens the latent period.

The shortening of latent period in mild hypoxia can be accounted for in either of two ways. First, $\mathrm{CO}_{2}$ might motivate the learned motor act because it is nociceptive sensory stimulus to upper airway receptors and, since mild hypoxia has been shown to increase sensitivity of some sensory modalities (Von Muralt, 1964), an increased aversive level in hypoxic environments could account for a shortening of latent period. Second and most likely, one might regard the ventilation of the animal as an indication of the drive level (motivation) existing in neural circuits involved in respiratory control and, if one assumes that this drive level governs both the somatic respiratory movements and the learned somatic motor act, then, any factors which tend to activate respiration (via these neural circuits) would also tend to activate the learned motor response. Although the stimulation of the peripheral chemoreceptors by mild hypoxia produces only a small immediate increase in ventilation it does produce a considerable increase in the ventilatory response to $\mathrm{CO}_{2}$ (Nielsen, 1952) and thus might be expected to decrease the latent period for learned escape (just as would an increase in $\mathrm{CO}_{2}$ concentration).

We have studied a somewhat analogous situation in which the sensitivity to $\mathrm{CO}_{2}$ was altered by an induced change in acid-base balance. In these studies the latent period decreased when the sensitivity to $\mathrm{CO}_{2}$ was increased by diminishing buffer base (Weinstein \& Riley, 1965; Travis, Wiley, Nechay, \& Maren, 1964).

The increase in latent period in severe hypoxia manifests itself in spite of the tendency of hypoxia to decrease latency. This increase in latent period is probably due to the impairment of both learned behavior (Gantt, Thorne, \& Dorrance, 1949) and motor behavior (Balke, 1964). At present we are not able to distinguish between the two in this situation.

On the basis of our findings concerning the effects of hypoxia, alterations of acid-base balance, intertrial interval, and stimulus strength upon learned escape from $\mathrm{CO}_{2}$, we believe that the neural mechanisms which mediate the somatic motor acts of respiration can be linked with the movement of other muscle groups through temporary (learned) connections in other areas of the central nervous system. This is reasonable from the evolutionary point of view, since in holothurians and cephalopods (McCutcheon, 1964) respiratory and locomotory activity are closely related and in many other species (some teleosts) the respiratory functions are closely related to motor acts designed to bring the animal into contact with the appropriate environment (surfacing activity of labyrinthine fishes). These learned motor acts which we have demonstrated in birds and rodents and which have been described in fish and turtles (Von Sommers, 1963) probably utilize neural circuits which have remained throughout several evolutionary stages and which allow the animal to govern not only its respiratory movements, but also its behavior in response to alterations in the respiratory environment.

\section{References}

Balke, B. Work capacity and its limiting factors at high altitude. Physiol. effects high Altitude. 1964, 233-247.

Gantt, W. H., Thome, G., \& Dorrance, C. Anoxia on conditional reflexes in dogs. Fed. Proc., 1949, 8, 53.

McCutcheon, H. F. Organ systems in adaptation. In The respira tory system. Handbook of Physiol., Amer. Physiol. Soc., 1964, 167-191.

Nielsen, M., \& Smith, H. Studies on regulation of respiration in acute hypoxia. Acta Physiol. Scand., 1952, 24, 293-313.

Travis, D. M., Wiley, C., Nechay, B. R., \& Maren, T. H. Selective renal carbonic anhydrase inhibition without respiratory effect: Pharmacology of 2-benzenesulfonamido- 1, 3, 4-thiadiazole5-sulfonamide (CL 11, 366). J. pharmacol. exp. Therap., 1964 , $143,383-94$.

Von Muralt, A. Where are we?: Short review of high altitude physiology. Physiol. effects high Altitude. 1964, 17-23.

Von Sommers, P. Air motivated behavior in turtles. J. comp. physiol. Psychol., 1963, 56, 590-596.

Weinstein, S. $\mathrm{O}_{2}$ and $\mathrm{CO}_{2}$ as reinforcers in conditioning. Fed. Proc., 1963, 22, 222.

Weinstein, S. Neural factors in control of respiration. Doctoral Dissertation, Johns Hopkins University, 1964.

Weinstein, S., \& Riley, R. L. Effect of hypoxia and renal carbonic anyhydrase inhibition upon learned escape from $\mathrm{CO}_{2}$. Fed. Proc., 1965.

Weinstein, S., \& Shepard, R. An apparatus for production of gas mixtures of controlled composition. J. appl. Physiol., 1963, 20, $552-554$.

\section{Noies}

1. Supported by U. S. A. Medical Research and Development Command Contract Number DA-49-193-MD-2726 and by Public HeaIth Service Grants HE 01929 , TG-HTS 5453 and HE 06945 and by ONR contract NR 102-101 and Wallace Laboratories.

2. Assistant Professor in Psychiatry and Environmental Medicine. 